\section{Chronic granulocytic leukaemia developing upon a follicular lymphoma}

Leukaemia has been reported ${ }^{1}$ recently in association with apparently unrelated haematological malignancies in patients treated with cytotoxic drugs. These leukaemias are mainly acute myeloid or variants such as acute myelomonocytic ${ }^{2}$ or erythroleukaemia. ${ }^{3}$ We describe a case of chronic granulocytic leukaemia (CGL) developing in a patient with a non-Hodgkin's lymphoma treated with alkylating agents, an association previously unreported.

\section{Case report}

A 57-year-old man presented in 1972 with a swelling on the right side of his neck. He had had a thoracoplasty for pulmonary tuberculosis 21 years previously. He had generalised lymphadenopathy, the glands being large, soft, and mobile, and massive splenomegaly to the level of the umbilicus. Blood count and film examination results were normal. A cervical lymph node biopsy showed the features of a giant follicular lymphoma. Treatment was started with cyclophosphamide, $50 \mathrm{mg}$ a day. He showed rapid improvement, and within six months there was neither lymphadenopathy nor splenomegaly. The patient continued on daily oral cyclophosphamide over the next three years without showing any clinical evidence of a lymphoma.

Early in 1976 slight cervical and submental lymphadenopathy recurred. A leucocytosis of $14.9 \quad 10^{9} / 1\left(14900 / \mathrm{mm}^{3}\right)$ was noted (see figure), the differential showing a neutrophilia and numerous myelocytes $\left(1.9 \cdot 10^{9} / 1\right.$ $\left(1900 / \mathrm{mm}^{3}\right)$. These findings were attributed to a respiratory infection. His condition gradually deteriorated until within six months he had pronounced cervical and submental lymphadenopathy, gross splenomegaly, a white cell count of $87.0 \times 10^{9} / 1\left(87000 / \mathrm{mm}^{3}\right)$ with a leucoerythroblastic blood picture, $66 \%$ neutrophils, $4 \%$ myelocytes, and a moderate thrombocytopenia $\left(85.0 \times 10^{9} / 1\left(85000 / \mathrm{mm}^{3}\right)\right)$. It was considered that the lymphoma had developed resistance to cyclophosphamide, the blood picture being caused by marrow infiltration. Treatment was changed to intermittent courses of chlorambucil and prednisolone, and while this produced slight improvement he soon deteriorated further, the white cell count rising to $104.0 \times 10^{9} / 1$ $\left(104000 / \mathrm{mm}^{3}\right)$ and the platelet count falling to $21.0 \times 10^{9} / 1\left(21000 / \mathrm{mm}^{3}\right)$ (see figure). An intensive search for tubercle or other infection proved negative. The leucocyte alkaline phosphatase score was reduced at 20 . Bone marrow examination showed a pronounced myeloid hyperplasia with a left shift in granulopoiesis, and preponderance of myelocytes. There was no evidence of bone marrow infiltration by lymphoma. Material was sent for chromosome analysis and this confirmed the presence of the Philadelphia chromosome.

Thus the diagnosis of chronic granulocytic leukaemia appeared established. It was decided to start treatment with busulphan immediately and not attempt any further investigations because of the severe thrombocytopenia. The patient showed rapid improvement within one month. Bruising cleared,

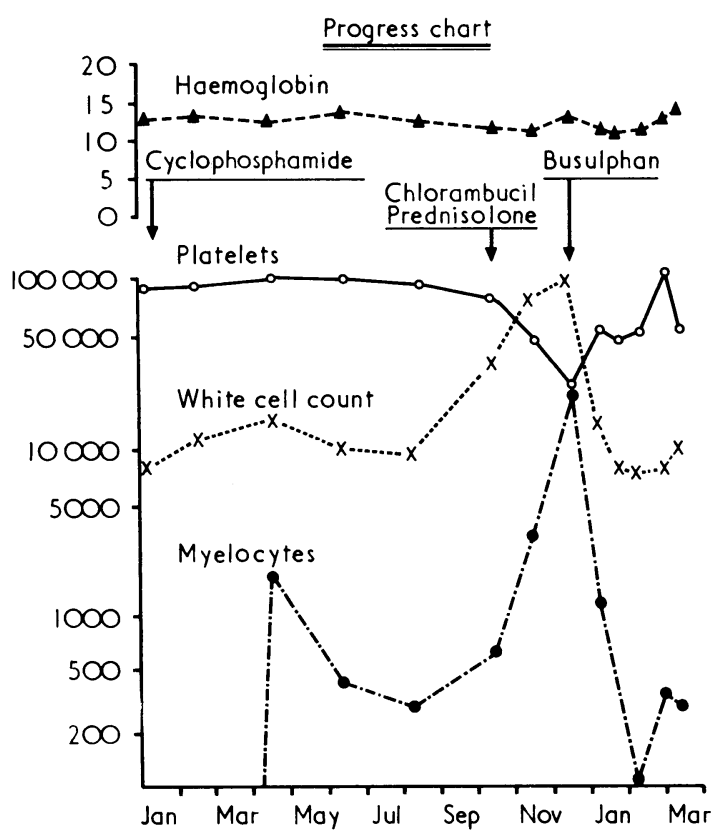

Progress chart showing peripheral blood counts and cytotoxic drug treatment. and there was no longer appreciable lymphadenopathy, but the spleen remained enlarged. The white cell count fell to $7 \cdot 1,10^{9} / 1\left(7100 / \mathrm{mm}^{3}\right)$, the differential cell count returned to normal, and the platelet count increased to $170.0 \times 10^{9} / 1\left(170000 / \mathrm{mm}^{3}\right)$ (see figure). Although this initial response is encouraging, insufficient time has elapsed to assess the eventual outcome.

\section{Discussion}

Acute myeloid leukaemia (or a close variant) is now a well-recognised complication of tumours treated by cytotoxic agents, although the exact relationship to the treatment remains uncertain. The development of chronic granulocytic leukaemia in such conditions, however, appears to be a rarity. A few cases have been reported linking multiple myeloma and myeloproliferative disorders, but no cases of CGL were described, most being polycythaemias. ${ }^{5}$ One case of Hodgkin's disease complicated by CGL has been reported, ${ }^{4}$ although this patient received radiotherapy.

A recent leading article ${ }^{1}$ reviewing acute leukaemia developing after cytotoxic treatment gave several explanations for such combinations of haematological disorders, which may equally well apply in this case. We suggest that the most probable explanation here is a second neoplasm in a patient developing chromosomal damage as a result of an alkylating agent. Thus this report serves as a further reminder of the diverse possible complications of long-term cytotoxic drug treatment.

1 Lancet, 1977, 1, 519.

2 Catovsky, D, and Galton, D A G, Lancet, 1971, 1, 478

${ }^{3}$ Cardamone, J M, Kimmerle, R I, and Marshall, E Y, American fournal of Medicine, 1974, 57, 836.

+ Swain, W R, et al, Cancer, 1971, 27, 569.

${ }^{5}$ Brody, J I, Beizer, L H, and Schwartz, S, American fournal of Medicine, 1964, 36, 315.

(Accepted 5 fuly 1977)

Department of Haematology, The Victoria Infirmary, Glasgow G42 9TY

J GORDON ERSKINE, MB, MRCP, senior registrar in haematology IAN WANG, MB, FRCP, consultant physician MARGARET M HUTTON, MB, MRCPATH, consultant haematologist

\section{Rubella virus isolation from cerebrospinal fluid in postnatal rubella encephalitis}

Neurological complications of postnatal rubella are rather rare with frequency figures varying from 1:400 to $1: 13000$ and with an average occurrence of $1: 6000$. So far only 125 cases have been reported. In none of these cases has rubella virus been isolated from cerebrospinal fluid (CSF) despite many attempts. ${ }^{12}$ It seems, therefore, worth reporting our successful isolation of rubella virus from the CSF of a patient presenting with the signs of rubella encephalitis.

\section{Case report}

A 14-year-old boy was admitted to the University of Modena Neurological Department in June 1976 because of sudden epileptic seizures. He had had a high temperature $(39 \mathrm{C})$ for three days and angina for 24 hours, with exanthema on face, trunk, and limbs. A few days before the onset of fever two relatives living with him had shown a rubella-like exanthema. When admitted to hospital he was drowsy and complaining of headache. In the evening he was hyperpyretic $\left(39.5^{\circ} \mathrm{C}\right)$, comatose with initial Cheyne-Stokes breathing, but without nuchal stiffness. Babinsky sign was present bilaterally, and the optic fundi were normal. A rubella-like exanthema was observed on face, trunk, and limbs. Submandibular and laterocervical nodes on both sides were affected. There was also erythematous angina.

The white cell count was $12.6 \times 10^{9} / 1\left(12600 / \mathrm{mm}^{3}\right.$ ) (neutrophils $55 \%$, lymphocytes $42 \%$, eosinophils $3 \%$ ) and ESR $30 \mathrm{~mm}$ in first hour. The lumbar puncture showed: clear CSF, isoelectric point $=42 \mathrm{~cm} \mathrm{H}_{2} \mathrm{O}$, Queckenstedt's sign negative; proteins $=0.6 \mathrm{~g} / 1(58 \mathrm{mg} / 100 \mathrm{ml}) ;$ glucose $=4.8 \mathrm{mmol} / 1$ $(86 \mathrm{mg} / 100 \mathrm{ml}) ;$ chloride $=115 \mathrm{mmol}(\mathrm{mEq}) / 1 ;$ Pandy $=+$, Nonne-Apelt + , sediment:19 cells, mainly monocytes. Diffuse spikes and waves were present on the electroencephalogram. 
Twenty-four hours after admission the patient showed moderate signs of meningeal irritation. He remained comatose for four days, then regained consciousness, but showed psychomotor agitation, mental confusion, and visual hallucinations. A gradual improvement was observed in the following days, and 20 days after admission he was discharged clinically recovered. Among virological tests, carried out by the virological service of the infectious and tropical diseases department, the haemagglutination-inhibition test for rubella, carried out on blood samples taken during the 20 days' stay in hospital, showed a clearcut increase of the antibody titres from 1/512 to $1 / 2048$. The complement fixation test results for measles, mumps, adenovirus, and herpes were negative. Lumbar puncture was carried out 24 hours after the onset of neurological symptoms. The CSF was inoculated into SIRC cells and monkey kidney cells at the patient's bedside. No cytopathic effects could be shown on monkey kidney cells, whereas the culture on SIRC cells showed cytopathic effects. A subculture was carried out on RK 13 and four days later a clear positive cytopathic effect was evident.

The virus was identified by the neutralisation test on RK 13 using a specific antirubella immunoserum diluted at $10^{11}$ and $10^{-2}$ titre.

\section{Comment}

The failure of previous attempts at isolating the virus from the CSF in acquired rubella encephalitis contrasts with the $33 \%$-positive isolation in congenital rubella. This may be due to the longer lifetime of the virus in the nervous system in cases of congenital rubella, ${ }^{3}$ but we should like to emphasise the relevance of technical problems. Most previous attempts at isolating the virus have been carried out under unfavourable technical conditions, such as shipment of the specimen, lack of appropriate cells for culture, collection of specimen in advanced stages of the disease, and when the presence of high specific antibody titre may interfere with recovery of the virus. ${ }^{1}$

A successful isolation of the virus from the CSF in acquired rubella requires not only specific cell lines (SIRC, RK 13, and Vero) but also the immediate inoculation of CSF into the cells. The location of a virology laboratory within the hospital (as occurs here) makes it easy to comply with this requirement.

The isolation of the virus from CSF, apart from its virological interest, may be relevant for understanding the pathogenesis of acquired rubella virus encephalitis. Direct viral invasion of the central nervous system has been considered as an alternative to activation of a latent encephalotropic virus or to immunologic processes as the mechanism underlying encephalitis. ${ }^{4}$ The recovery of rubella virus in CSF supports the view that direct virus invasion of the central nervous system does in fact occur.

${ }^{1}$ Rose, H D, American fournal of Medicine Sciences, 1974, 268, 287.

2 Connolly, J H, et al, Brain, 1975, 98, 583.

3 Rawls, R E, Progress in Medical Virology, 1974, 18, 273.

${ }^{4}$ Cifarelli, P S, and Freirich, A W, New York State Fournal of Medicine, 1966, 66, 1117.

(Accepted 14 fuly 1977)

Department of Infectious and Tropical Diseases, University of Modena, Modena, Italy

F SQUADRINI, MD, professor, director of the department of infectious and tropical diseases

F TAPARELLI, MD, professor

B DE RIENZO, MD, assistant professo

G GIOVANNINI, MD, staff member

Department of Neurology, University of Modena, Modena, Italy C PAGANI, MD, staff member

\section{Meningococcal pericarditis without meningitis}

The number of reported cases of meningococcal pericarditis without clinical evidence of meningitis is very small. We report a further case additionally complicated by peritonitis, arthritis, and urethritis.

\section{Case report}

The patient was a 14-year-old Negro schoolboy. Five weeks before admission he spontaneously developed painful swelling of his right knee, lasting five days before resolving completely. The night before admission he suffered a rigor and woke with severe retrosternal chest pain exacerbated by respiration and movement. He also admitted to generalised abdominal pain and to a painful right ankle. He denied any headache or neck stiffness. $\mathrm{He}$ and his family were living in council accommodation in East London. Neither he nor his family had travelled abroad in the previous year.

$\mathrm{He}$ was distressed and dyspnoeic with an oral temperature of $38^{\circ} \mathrm{C}$. No rash, lymph node enlargement, or abnormality of the mucous membranes was detected. Chest examination showed left basal dullness and bronchial breathing (see figure). The pulse was regular at $120 / \mathrm{min}$ with a lying blood pressure of $110 / 70 \mathrm{~mm} \mathrm{Hg}$; the venous pressure was raised $3 \mathrm{~cm}$ without paradoxical respiratory change; and the apex beat displaced $2 \mathrm{~cm}$. A loud pericardial rub was audible. The abdomen was tense with guarding and reduced bowel sounds. The right ankle was swollen, hot, and tender. Neurological examination showed no abnormalities and, in particular, there was no neck stiffness.

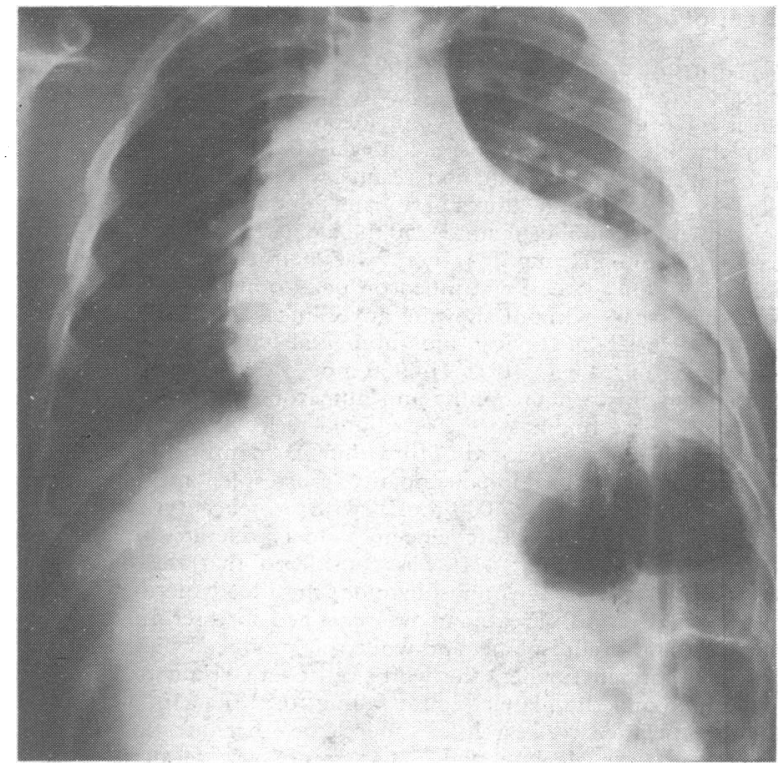

Chest radiograph on admission showing a large pericardial effusion.

Initial investigations showed haemoglobin: $14.9 \mathrm{~g} / \mathrm{dl}$; white cell count: $15.7 \times 10^{9} / 1\left(15700 / \mathrm{mm}^{3}\right)(93 \%$ neutrophils $)$; repeated blood cultures: negative results on days 1 and 2 of admission; chest radiography: enlargement of the heart with collapse and consolidation of the left lower lobe; and electrocardiogram: widespread ST elevation consistent with acute pericarditis.

In the next 12 hours he deteriorated with increasing dyspnoea, development of pronounced pulsus paradoxus, and further raising of venous pressure. Percutaneous needle aspiration was performed to relieve the tamponade and $150 \mathrm{ml}$ of serosanguinous fluid obtained. Gram stain showed profuse polymorphs with intracellular Gram-negative diplococci. Culture grew Neisseria meningitidis, identified by fermentation reactions and by positive agglutination with meningococcal type $\mathrm{C}$ antisera. Disc diffusion methods showed sensitivity to penicillin, cephaloridine, and sulphafurazole. A urethral smear on the second day showed scanty pus cells and a few intracellular diplococci, which failed to grow on culture. Further questioning disclosed no history of dysuria, urethral discharge, or sexual activity. Needle aspiration of peritoneal fluid also disclosed a pronounced neutrophil leucocytosis but without identifiable organisms. Culture of postnasal swabs from the patient and his family failed to show meningococci.

After pericardial aspiration he received parenteral cephaloridine, $1 \mathrm{~g}$ four times a day (because of penicillin sensitivity), and sulphadimidine, $1 \mathrm{~g}$ four times a day, but within 24 hours tamponade recurred. An indwelling percutaneous pericardial drain was therefore inserted and $1500 \mathrm{ml}$ of pus drained during the next five days. After this he made an uneventful recovery and remains clinically normal six months later.

\section{Comment}

Neisseria meningitidis infection has widespread manifestations, including urethritis, ${ }^{1}$ arthritis, and pericarditis. Pericarditis accompanying meningococcal meningitis is uncommon but recognised. Pericarditis occurring as the major feature of a meningococcal infection without clinical meningitis is much rarer, and we have found only nine such cases reported. ${ }^{2-5}$

Pericarditis has been considered to be a later manifestation of meningococcal infection resulting as part of a "polyserositis" from a supposed hypersensitivity to the organism or to endotoxin. ${ }^{4}$ Others, 